\title{
Análisis crítico del discurso de políticas públicas en diversidad sexual en Chile*
}

\author{
Critical Discourse Analysis from Public \\ Policy of Sexual Diversity in Chile
}

Recibido: 1 de marzo de 2015 | Revisado: 1 de junio de 2015 | Aceptado: 1 de agosto de 2015

\author{
GENOVEVA ECHEVERRÍA ** \\ JosÉ MARTín MATURANA \\ Universidad Academia de Humanismo Cristiano,
}

Santiago, Chile

doi:10.11144/Javeriana.up14-4.acdp

Para citar este artículo: Echeverría, G., \& Maturana, J. M. (2015). Análisis crítico del discurso de políticas públicas en diversidad sexual en Chile. Universitas Psychologica, 14(4), 1485-1498. http:// dx.doi.org/10.11144/Javeriana.up14-4.acdp

\footnotetext{
* Agradecimientos

*** Autor correspondiente. Correo electrónico: genovevaecheverria@yahoo.com
}

\begin{abstract}
RES UMEN
La investigación analiza las últimas políticas públicas relacionadas con la diversidad sexual producidas en Chile en los últimos cinco años. Se revisan las posiciones de poder, las versiones de sexualidad, las normalizaciones y los estereotipos de género que permanecen presentes en estos planes. Desde una perspectiva cualitativa, se utiliza el Análisis Crítico del Discurso para analizar cuatro iniciativas generadas en el sector salud, educación y derechos ciudadanos. Los resultados evidencian la presencia del marco heteronormativo y la fuerza del control de la sexualidad y los cuerpos en estos programas y leyes, lo que dificultaría que los sujetos logren un reconocimiento desde un lugar de agencia y poder.

Palabras clave

diversidad sexual; políticas públicas; análisis crítico de discurso; regulaciones de género
\end{abstract}

\section{A B S T R A C T}

This research analyzes recent public policy measures related to sexual diversity generated in Chile in the last five years. Power positions, versions of sexuality, normativity and gender stereotypes that remain present in this policies are reviewed. From a qualitative perspective, the Critical Discourse Analysis is used to analyze four initiatives generated in the health sector, in the education sector, and in the citizen rights sector. The results show the clear presence of the heteronormative frame and a strong control of sexuality in this policies and laws, something which would difficult the subjects achieving recognition from a position of agency and power.

Keywords

sexual diversity; public policy; critical discourse analysis; gender regulation 
El tema de la diferencia se ha posicionado como un ámbito de estudio y de preocupación sociopolítica en América Latina a partir de los aportes del pensamiento poscolonial, el posfeminismo, las teorías del reconocimiento, el interculturalismo, la Teoría Queer y los teóricos de la posmodernidad, pero también fruto de una lucha constante de grupos organizados de minorías culturales (Kozak, 2006). En este escenario, la problemática particular de la diversidad sexual se ha hecho visible como un tema ineludible dentro de la agenda social y pública de nuestras sociedades (Toro-Alfonso, 2012).

Durante el último quinquenio hemos visto en Chile una fuerte arremetida de movimientos y agrupaciones sociales que abogan por los derechos de lesbianas, gais, bisexuales, transexuales e intersexuales (LGBTI). Es así que, el último Informe de Derechos Humanos de la Diversidad Sexual reconoce avances en materia de políticas públicas y de derechos en los ámbitos de salud, gendarmería, educación, derechos y leyes, entre otros (Movimiento de Integración y Liberación Homosexual [Movilh], 2014). Sin embargo, estos logros no están exentos de controversias, en la línea de cuestionar el lugar del Estado en la institucionalización de la sexualidad (Rivas, 2014).

Los estudios revisados critican las políticas públicas iberoamericanos en torno a la inclusión de diversidad, acusándolas de reduccionistas y minimizadoras de la real importancia social del problema (Alfaro \& Zambrano, 2009; Cunial \& Palumbo, 2014; Esguerra \& Bello, 2014; Flores, 2011; Forero \& Hurtado, 2013; Kozak, 2006; Lahera, 2008; Rozas, 2014; Toro-Alfonso, 2012). Así, se denuncia que en estas impera la lógica de la heterosexualidad masculina, con políticas de género que se han enfocado principalmente a las dinámicas de inequidad y discriminación entre hombres y mujeres heterosexuales (Forero \& Hurtado, 2013; Lahera, 2008). Se acusa también el uso de marcos heteronormativos en las políticas públicas en pro de los grupos LGTBI (Cunial \& Palumbo, 2014) y la presencia de nuevas formas de prácticas discriminadoras hacia las personas con diversidad sexual (Toro-Alfonso, 2012). En suma, se constata que las personas LGTBI aparecen como la otredad, desde una lógica de poder y subordinación que los deslegitima como sujetos de derecho (Esguerra \& Bello, 2014).

¿Cómo podemos explicar estas resistencias a pesar de la mayor conciencia y aparente preocupación de nuestras sociedades por abrirse a incluir la diversidad? Butler (2007) plantea que los sujetos se construyen desde normas que los preceden y exceden, por lo que se hace complejo generar regulaciones que logren romper los regímenes de verdad, ya que esto implicaría poner en cuestión las verdades de los mismos sujetos que intentan luchar contra dichas normas. Sin embargo, si bien las normas proporcionan un marco, no nos determinan; es aquí donde Butler aboga por la posibilidad de agencia que tienen los sujetos para generar aperturas o para, desde Braidotti (2000), trabajar por la construcción de nuevos sujetos deseantes.

Estas posibilidades de generar transformaciones se complejizan cuando, al situarse desde una perspectiva crítica, se puede afirmar que el principio normalizador suele permanecer implícito en las regulaciones, siendo difíciles de leer los efectos que producen, naturalizando las mismas nociones que se buscan cuestionar (Braidotti, 2000; Butler 2007, 2009a, 2009b).

En esta línea, la psicología comunitaria crítica ha denunciado que las políticas sociales en América Latina han trabajado preferentemente disponiendo a sus destinatarios como carentes y deficitarios, despojándolos así de derechos y autonomía (Alfaro \& Zambrano, 2009; Rozas, 2014). Por otra parte, se cuestiona el generalizado enfoque de multiculturalidad, por considerar que este naturaliza las relaciones, invisibilizando las desigualdades y el conflicto. Se propone entonces, trabajar por la interculturalidad y el reconocimiento (Rozas, 2014), construyendo una psicología contrahegemónica, que permita lecturas y prácticas que interpelen a las estructuras de dominación a fin de develar los fundamentos opresivos, discriminadores y excluyentes amparados en dichas regulaciones (Flores, 2011).

¿Qué podemos hacer, entonces, desde las ciencias sociales para visibilizar esos elementos de sujeción y control que permanecen bajo la aparente apertura y respeto de ciertas libertades de nuevas políticas y discursos progresistas? El presente artículo se orienta 
precisamente dentro de los esfuerzos de una psicología crítica que busca aportar en un itinerario que promueva la inclusión de la diferencia, trabajando desde dispositivos que superen lo explícito y que, auscultando desde la sospecha, examinen las políticas públicas a fin de exteriorizar los mecanismos de dominación, discriminación y control que portan de manera tácita y entretejida en sus redes discursivas (Stecher, 2010; Van Dijk, 2000).

En esta línea, se presenta un análisis de los textos que sustentan las principales políticas públicas relacionadas con el tema de derechos de LGTBI, que se promulgaron en Chile entre el 2010 y 2015. Para esto, se usa como método el Análisis Crítico del Discurso (ACD), precisamente para realizar una lectura del poder hegemónico que se instala en estos textos (Stecher, 2010; Van Dijk, 2000), a fin de transferir poder a las personas y comunidades (Alfaro \& Zambrano, 2009; Flores, 2011).

El objetivo de este estudio, en consecuencia, se dirige a evidenciar elementos hegemónicos, naturalizadores y heterosexistas que se encuentran presentes en la textualidad de las normativas mencionadas y que podrían dificultar que estas políticas promuevan una real defensa de derechos e inclusión de las personas LGTBI. Así, las preguntas directrices se orientan a revisar en estos planes y leyes: ¿Cómo circula el poder?, ¿Quiénes lo detentan?, ¿Qué lugares son asignados a los distintos actores?, ¿Qué nivel de agencia/pasividad se construye para las personas con diversidad sexual?, iSe supera la heternormatividad?, iSe logran sobrepasar las normalizaciones y binarismos para proponer e incluir una nueva noción de diversidad sexual?, ¿Cómo se trabajan las nociones de diferencia, discriminación e inclusión?, ¿Se traspasan los estereotipos clásicos y reificadores de la sexualidad y la diferencia?, iSe abre el discurso reflejando y promoviendo una transformación y apertura?

\section{Desatar los cuerpos}

En Chile, se vive una constante situación de discriminación homofóbica y transfóbica, tanto en las esferas privadas como públicas; así se indica que el $74.5 \%$ de la población LGTBI ha sido discriminada al menos una vez en su vida; se añade que muy pocos casos de homofobia y transfobia judicializados en el 2013 lograron alcanzar justicia (Movilh, 2014). La violencia hacia las personas LGBTI se funda desde las representaciones, estereotipos, categorías y repertorios discursivos propios de las culturas, pero también es desde los poderes públicos que se norman los deseos, aversiones y acciones ciudadanas, donde la heteronorma se cuela por las nociones de género establecidas e institucionalizadas, lo cual genera un contexto social que hace posible la discriminación legitimándola (Butler, 2007; ToroAlfonso, 2014).

En esta misma línea, la psiquiatría se erige como un ente incuestionable de poder que opera como censor normalista, generando performativamente realidades que actúan hacia la exclusión de las identidades y acotando las sexualidades dentro de categorizaciones instituidas como aceptables (Butler, 2007; Martínez-Guzmán \& Íñiguez-Rueda, 2010). Estas y otras regulaciones subjetivan y normalizan a través de prácticas sociales que muchas veces operan de formas implícitas, difíciles de leer y discernir (Butler, 2009a).

Los grupos LGTBI han ido posicionando sus demandas de reconocimiento como sujetos de derecho, pero Butler (2007) advierte que cuando estos grupos intentan la construcción de una identificación contraria a la opresiva, reproducen la misma lógica y binarismos heteronormativos que pretenden superar. Por lo mismo, si se busca romper la hegemonía reificadora que norma los cuerpos y regula los deseos, se hace necesario abrir nuevas categorías y propuestas que subviertan las representaciones convencionales de la subjetividad, sugiriendo nuevas formas de materialismo corporal (Braidotti, 2000).

La transexualidad ${ }^{1}$ aparece como un espacio de transgresión de las normas de género, impo-

1 La categoría transexualidad refiere a personas que se sentirían identificadas con el género contrario al de su sexo genital. Dentro de este grupo se puede distinguir a los transgéneros, quienes no buscan modificar su cuerpo para que corresponda al género con el que se identifican. Esta distinción es escasamente reconocida y usada. Si bien lo trasgénero aporta matices de relevancia, para el presente artículo se usará indistintamente y como similares las nociones transexual, transgénero y persona trans. 
sibilitando constituir definiciones estables, coherentes y fundadas en sustentos naturales (Martinez-Guzmán \& Iñiguez-Rueda, 2010). Aquella subversión genera que la biopolítica los castigue desde la heterosexualización y normalización de estos cuerpos; generando odio y rechazo hacia su propia genitalidad, logrando solo a través de la intervención quirúrgica y hormonal la aceptación social (Coordinadora Universitaria por la Disidencia Sexual [CUDS], 2011).

Las posfeministas cuestionan el mismo concepto de género, en vías a romper las categorías y sus efectos reificantes, instalando la noción de disidencia sexual. Al apropiarse de otro lenguaje taxonómico se podría derrocar la coerción de los tránsitos médicos, psicológicos, jurídicos y políticos que tachan las ambigüedades y fluideces de sexos, géneros y deseos (CUDS, 2011). En coherencia, desde el posestructuralismo se intenciona la construcción de nuevos sujetos deseantes y nómades, sin una unidad esencial y contra ella; buscando la desidentificación del monologismo falocéntrico (Braidotti, 2000).

\section{Políticas sociales y prácticas de regulación}

Las políticas públicas son hechos discursivos sostenedores de actos de poder, ya que al provenir desde una fuente estatal se instalan desde una lógica de obligatoriedad, donde el afectado tiene que aceptar el criterio social existente (Díaz-García, 2013; Forero \& Hurtado, 2013; Rozas, 2014). En este contexto, se ha indicado que las políticas públicas en torno al género se han orientado a estudiar y describir las situaciones de inequidad pero sin preguntarse acerca de las representaciones sociales que éstas portan (Forero \& Hurtado, 2013). Así, las regulaciones de dominación y exclusión que estas normativas tramitan no son visibilizadas, dificultando el develar los efectos de poder que se cuelan más allá de lo explícito, donde la explosión discursiva se convierte en el mecanismo por excelencia de control (Forero $\&$ Hurtado, 2013; Mogrovejo, 2008).

Por otra parte, se denuncia que las políticas sociales han operado en contra de la legitimación de las mismas personas hacia las cuales se pretende ayudar; el sujeto de estos programas ha sido definido y encasillado como carente, incapacitado y deficitario, desvinculándolo además de sus costumbres, historia y prácticas culturales; despojándolo así de las posibilidades de autonomía y agencia que podría tener como actor social (Alfaro \& Zambrano, 2009; Butler, 2009a; Rozas, 2014). Desde allí, se propone que las políticas sociales de género se orienten a resignificar y superar el esquema binario de género a través de la creación de categorías y discursos alternativos, incluyentes y que no reproduzcan el imaginario social existente, coartando y delimitando el poder de quienes portan los mecanismos de control social y sancionan los límites de la expresiones de la sexualidad (Forero \& Hurtado, 2013; GarcíaDíaz, 2013). En esta línea, se insertan las iniciativas promovidas por una psicología contrahegemónica que reivindica el respeto de la dignidad humana y el reconocimiento de la diferencia como principio comunitario (Flores, 2011; Rozas, 2014) y que "se compromete en el análisis de las estructuras de dominación y el sustento ideológico del sistema de opresión y exclusión social” (Flores, 2011, p. 70).

\section{El Análisis Crítico del Discurso como estrategia disidente}

Es posible señalar que el discurso construye, constituye, cambia y define las estructuras sociales desde las interacciones cotidianas. Por lo mismo, es relevante evidenciar el poder del discurso que aparece en el enfrentamiento de las estrategias que los actores sociales e institucionales utilizan dentro de un campo. Estas hablas que enlazan saberes y poderes poseen una doble condición de poder: de sujeción y de resistencia. Entonces, si bien los sujetos solo pueden generar y leer textos disponibles y legitimados históricamente en su espacio social, existen posibilidades de innovación desde la heterogeneidad de los órdenes del discurso y desde la agencia de los actores (Stecher, 2010; Van Dijk, 2000).

En esta misma línea, a (2009) indica que las formas de resistencia y subversión pueden operar desde las mismas lógicas normativas; así, a través de los actos de repetición (performativos) se permiten subversiones que avanzan a la deconstrucción de 
las normas sociales. Con esta línea argumentativa, Butler enfatiza no solo la fuerza de los discursos hegemónicos, sino también la capacidad de agencia y transformación de los sujetos.

En este contexto, se inscribe el ACD, como estrategia y mirada teórica a la vez; considerando al lenguaje como práctica social en sus contextos de uso y conexión con relaciones de poder. Se entiende al discurso como un momento de la vida social que tiene efectos y es afectado por otros elementos no discursivos, por eso este se analiza no por el discurso mismo, sino por la ideología y formas en las que mantiene la dominación a través de la instalación de sentidos. En consecuencia, esta óptica investigativa conlleva un compromiso explícito con los sujetos sociales más desfavorecidos; buscando desde allí propiciar una apertura hacia posibilidades de resistencia (contradiscursos, discursos alternativos) ante los marcos culturales hegemónicos que contribuyan a la democratización y emancipación de la sociedad (De la Fuente García, 2004; Forero \& Hurtado, 2013; Martín Rojo, 2003; Stecher, 2010; Van Dijk, 2000).

\section{Método}

Considerando el problema de investigación, se ha optado por un diseño de estudio de casos y en un enfoque metodológico cualitativo (Krause, 1995). Desde una perspectiva discursiva, se trabaja con el dispositivo del Análisis Crítico de Discurso (ACD), que plantea la inexistencia de una neutralidad de los discursos y reconoce que estos se inscriben en el contexto de quiénes son los personajes que enuncian los discursos, a qué grupos representan y cuál es la carga de sentidos que traen. Es así como a través del ACD, se ha buscado evidenciar los efectos de poder en los textos de estas políticas (De la Fuente García, 2004; Forero \& Hurtado, 2013; Martín Rojo, 2003; Stecher, 2010; Van Dijk, 2000).

\section{Corpus textual}

Para la elección de las fuentes, se realizó un muestreo intencionado de políticas públicas, cuyos criterios de elección fueron: a) que estuvieran destinadas directa o indirectamente a intervenir a favor de los derechos de las personas de diversidad sexual; b) que hubieran sido promulgadas en los últimos cinco años y c) que pertenecieran a sectores de relevancia social, evidenciándose esto porque fueron propuestas o respaldadas por organizaciones pertenecientes a los grupos LGTBI (Movhil, 2014). Dentro de este marco, se escogieron los siguientes documentos pertenecientes a salud, educación y derechos civiles:

1. Vía clínica para la adecuación corporal en personas con incongruencia entre sexo físico e identidad de género (VCAC). Se refiere a la estrategia de atención e intervención en las situaciones de cambio corporal para transexuales, publicado por la División de Prevención y Control de Enfermedades del Ministerio de Salud en 2010.

2. Discriminación en el contexto escolar, orientaciones para promover una escuela inclusiva (DCE): el Ministerio de Educación lo publica y distribuye en 2013 como un texto sugerido para colegios y liceos de Chile..

3. Ley de no discriminación (LND). En el año 2012 se promulga la Ley 20.609 que "establece medidas contra la discriminación por la antidiscriminación" y que integra la defensa ante diversas situaciones de discriminación.

4. Acuerdo de Unión Civil (AUC). Es la ley que permite hacer un contrato entre dos personas de igual o del mismo sexo, que comparten hogar, que busca regular los efectos jurídicos y patrimoniales. Fue aprobada por el Congreso en enero del 2015.

\section{Procedimiento de análisis}

En el marco del ACD, se trabajó desde la propuesta de modelo tridimensional de Stecher (2010), quien a su vez complejiza la matriz original de Fairclough (1989 citado en Stecher, 2010). Su primer nivel textual se orienta a diferenciar y distinguir los principales significados y representaciones. La segunda dimensión de las prácticas discursivas busca dar cuenta de cómo y a través de qué estrategias discursivas se abren y cierran lecturas, vehiculizando diferentes órdenes del discurso. Y la tercera dimensión es el análisis social explicativo de los eventos discursivos 
que participan en los procesos de producción, sosteniendo o transformando las formas de dominación imperantes en un determinado dominio (Stecher, 2010). La matriz propuesta por los autores se complementó explicitando los elementos y estrategias que se consideraron pertinentes para el actual problema de investigación, que se suman a partir de una amplia revisión de otros trabajos teóricos y aplicados de ACD (Butler, 2009a; Forero \& Hurtado, 2013; Martínez-Guzmán \& Íñiguez-Rueda, 2010; Potter, 1998; Van Dijk, 2000).

El trabajo analítico se llevó a cabo aplicando la matriz adaptada a cada uno de los documentos por separado. En cada caso se eligieron las estrategias discursivas pertinentes a fin de responder a las preguntas directrices del modelo; sin embargo, como en todo análisis del discurso la labor analítica se realiza con el texto como totalidad, por lo que siempre se consideró a los textos como objetos completos y no fragmentarios.

\section{Resultados}

A continuación, se presenta una síntesis de los principales hallazgos a partir del amplio material generado con el ACD; esta integración se construyó a la luz de los objetivos y preguntas directrices.
Para identificar los documentos, en esta presentación se utilizan las siglas de las fuentes: VCAC, DCE, LND, AUC. Se señalan los niveles (NT, ND, NPS) y estrategias discursivas que se están utilizando en los distintos momentos; en el intento de superar las falencias de opacidad que tienen algunas comunicaciones investigativas de enfoque cualitativo, asumiendo el criterio de rigor de transparencia como correlato de confiabilidad (Krause, 1995). También, se introducen segmentos de los documentos (entre comillas) a fin de fundamentar y generar un diálogo con la textualidad examinada.

\section{Los significados de la diversidad sexual}

Si bien en los textos se presentan varias definiciones de manera explícita, estos significados están atravesados por el tejido discursivo que porta otras regulaciones.

\section{La diversidad se refiere a "los otros"}

En el texto escolar (DCE) al hablar de la diferencia y diversidad en las personas (NT) se señala: "conversar sobre las diferencias, conocer y escuchar al otro, son experiencias que ayudan a acercarse a lo desconocido"; se habla así a un supuesto interlocu-

TABLA 1

Matriz tridimensional de ACD adaptada

\begin{tabular}{|c|c|c|}
\hline $\begin{array}{l}\text { Nivel del discurso } \\
\text { Operación analítica }\end{array}$ & Elementos y estrategias con los que trabaja & Preguntas orientadoras \\
\hline $\begin{array}{l}\text { Textual (NT) } \\
\text { (Descripción, análisis } \\
\text { lingüístico) }\end{array}$ & $\begin{array}{l}\text { Significados presentes: } \\
\text { Conceptos, informaciones presentes y } \\
\text { ausentes, representaciones sociales, sujetos y } \\
\text { contextos implicados. }\end{array}$ & $\begin{array}{l}\text { ¿Qué sentidos y significados (nociones, } \\
\text { sujetos, representaciones, contextos) son } \\
\text { distinguibles como elementos que propone } \\
\text { y moviliza el texto? }\end{array}$ \\
\hline $\begin{array}{l}\text { Discursivo (ND) } \\
\text { (Interpretación, } \\
\text { análisis intertextual) }\end{array}$ & $\begin{array}{l}\text { Estilos, géneros y discursos de un orden del } \\
\text { discurso: } \\
\text { Repertorio interpretativo, reificar, sujetos } \\
\text { y sus posiciones de poder, implicaturas, } \\
\text { reportes factuales (discurso empirista), } \\
\text { consenso tácito, tensiones discursivas, } \\
\text { contradicción performativa. }\end{array}$ & $\begin{array}{l}\text { ¿Qué y cómo utiliza las estrategias } \\
\text { discursivas para construir el texto? } \\
\text { ¿Cómo tramita el poder desde los recursos } \\
\text { discursivos? ¿Qué voces son posicionadas } \\
\text { desde lugares de poder? ¿A través de qué } \\
\text { recursos abre y cierre posibilidades de } \\
\text { lectura y acción? }\end{array}$ \\
\hline $\begin{array}{l}\text { Práctica social (NPS) } \\
\text { (Explicación, análisis } \\
\text { social) }\end{array}$ & $\begin{array}{l}\text { Efectos de poder social: } \\
\text { Legitimaciones, agencia y precariedad de } \\
\text { sujetos, efectos de poder, regulaciones de } \\
\text { género y normalización, reificaciones. }\end{array}$ & $\begin{array}{l}\text { ¿Cómo contribuye a reconocer o } \\
\text { deslegitimizar a las diversidades sexuales, } \\
\text { desde las hegemonías y actores que } \\
\text { moviliza, y desde las tensiones discursivas } \\
\text { que sostiene? }\end{array}$ \\
\hline
\end{tabular}

Fuente: Stecher (2010) 
tor que se reconoce como un nosotros los semejantes para invitarlo y persuadirlo a abrirse a lo desconocido: los diversos. No se habla directamente a los niños indígenas, homosexuales y con discapacidad; se dirige a un lector que refiere al sujeto hegemónico (ND) de la norma, con el que se establece la alianza de conjugar el nosotros; quedando los diversos como los otros, lo abyecto. Así, (NPS) se excluye en el mismo intento discursivo de incluir.

\section{Ser trans como una patología}

En la VCAC se indica que para acceder al tratamiento de adecuación corporal, el equipo de salud mental deberá diagnosticar y "Establecer la presencia de incongruencia entre identidad de género y sexo físico y grado de afectación”. Entonces, se reifica como una categoría diagnóstica (ND) como una verdad que determina lo normal o anormal. El sentimiento hacia su cuerpo, la identidad hacia un género son definidos como incorrectos.

\section{Enfermos de baja categoría}

Si bien existe ahora un procedimiento y normativa (VCAC) para que las personas trans tengan acceso a lograr el cuerpo que ellos sienten como propio, también se indica que dada la baja prevalencia de esta condición no existe una dotación adecuada de equipos preparados para proveer esta atención; por tanto, lo que queda es que la persona transexual (NT) "deberá competir con la demanda de camas de Urología” y "también deberán competir con demanda de patología mamaria”. Así, una implicatura o inferencia (ND) nos evidencia que este diagnóstico ocupa un bajo lugar dentro de la jerarquía del sector salud, situando a las personas trans como usuarios de "bajo rango" (NPS). La transexualidad se construye entonces como una enfermedad "cuestionable", distinta a las enfermedades "dignas", de ahí sus menores derechos.

\section{Los más diferentes dentro de los diversos}

Si bien la ley de AUC permite a dos personas independientemente de su sexo- acceder a ser convivientes civiles, llama la atención que en la presentación que se ha hecho de este proyecto desde el mismo Congreso se señala que es un "Pacto de Unión Civil [que] pone fin a una lógica de exclusión de las parejas de hecho, tanto homosexuales como heterosexuales, dándoles un reconocimiento social". Así, este enmarque del AUC (NT) no es inclusivo de todas las personas LGTBI, sino solo de los sujetos homosexuales; cayendo así dentro de una lógica binaria (ND) que admite solo una recategorización que incluya heterosexuales y homosexuales: se generan nuevas hegemonías dentro del mismo grupo LGTBI.

\section{Los lugares del poder: pasividad y agencia en juego}

Las políticas públicas emanan del Gobierno y sus distintos estamentos, por lo mismo todo programa o directriz está determinada a ser una norma de control o, al menos, de institucionalización de una cierta forma de regulación de la vida de las personas. Sin embargo, al Estado también le cabe el rol de reconocimiento y entrega de derechos a los sujetos y colectivos de la sociedad.

\section{Los dueños del poder}

En el documento de la Vía Clínica (VCAC) es el sujeto que enuncia y desde donde emana el instructivo del Ministerio de Salud. Dentro del personal descrito para esta tarea se encuentran psiquiatra, psicólogo y otros profesionales de la salud; sin embargo, se indica que para la decisión de la "Confirmación de criterios de elegibilidad y disposición para otras intervenciones: Médico psiquiatra...", será el médico del equipo quien decida sobre si la persona trans puede acceder a su derecho y quien decide si estos usuarios deben recibir psicoterapia o no. Se centraliza el poder (NPS) desde la jerarquía dominante y unipersonal.

El saber médico es sostenido además por otra fuente de poder dominante: la ciencia. "Para establecer la presencia de incongruencia entre identidad de género y sexo físico y su grado de afectación, 
se recomienda el empleo de parámetros específicos. Pueden servir como referencia los criterios mencionados en el DSM-IV o la Clasificación Internacional de Enfermedades décima versión (CIE-10)”. Así el enunciador utiliza la ciencia como una "autoridad externa e incuestionable" (ND), desde la cual se fundan las decisiones y procedimientos; a través del uso de tecnicismos científicos y formas gramaticales propias del discurso empirista y usando el consenso tácito, se impone un acuerdo social que imposibilita el disenso (NPS).

Otro alto lugar de poder en nuestra sociedad: el juez. Evidentemente en el texto de la LND es el juez quien debe determinar una serie de acciones. Pero esto se incrementa por existir muchos aspectos indefinidos o vagamente descritos: "Para los efectos de esta ley, se entiende por discriminación arbitraria toda distinción, exclusión o restricción que carezca de justificación razonable (...) en particular cuando se funden en motivos tales como la raza o etnia, (...), la orientación sexual, la identidad de género (...). Las categorías a que se refiere el inciso anterior no podrán invocarse, en ningún caso, para justificar, validar o exculpar situaciones o conductas contrarias a las leyes o al orden público". Aquí, si bien se enumeran una serie de situaciones como fundamentos de discriminaciones, también se usa al comienzo la expresión "en particular", fórmula (ND) que relativiza lo dicho dejándolo todo como meros ejemplos. Luego, se señala la posible negación de dichas categorías, si se contraponen a otras leyes, rebajando el poder y fuerza de la misma normativa (NPS).

\section{Niños vulnerables, adultos responsables}

En el plan contra la discriminación (DCE), al identificar qué sujetos son incluidos (NT) se mencionan los adultos, estudiantes, docentes, equipo psicosocial, familia, comunidad educativa. Sin embargo, en el texto se habla principalmente de docentes y estudiantes. Así "son los adultos quienes deben traducir en acciones y actitudes concretas el respeto por la diversidad", los adultos/docentes aparecen (ND) como sujetos de deberes pero no de derechos. Los adultos actúan tanto para generar discriminación como para realizar acciones para superarla. No aparece la posibilidad que los adultos sean objeto de discriminación, menos aún como estudiantes. Por su parte, los estudiantes (niños y jóvenes) solo se muestran como sujetos de derechos y no de deberes y necesitados de protección. Los estudiantes son marcados como vulnerables, ya que aprenden repitiendo los modelos de los docentes: se los desresponsabiliza y se los instala en la pasividad.

Al hablar de las situaciones de discriminación, en el texto DCE se aprecia que algunos sujetos son nombrados, mientras otros son negados. Se señala (NT): "víctimas habituales de la discriminación", "las actitudes hostiles que se producen ante esta diversidad", "las manifestaciones de discriminación". Así, se menciona al sujeto víctima, pero en la oración (ND) se suplanta al sujeto en tanto otro estudiante que actuó con bullying contra este compañero, por las acciones que se nombran como actitudes y manifestaciones, confiriéndole agencia a estas últimas. El lugar del sujeto que discrimina queda vacío, lo que impide la posibilidad de generar conciencia de la propia conducta (NPS); quedan los estudiantes como víctimas o sujetos de precariedad.

\section{Los diversos despojados de agencia}

En la VCAC se indica: "El inicio del manejo hormonal en personas con incongruencia entre identidad de género y sexo físico se encuentra condicionada al cumplimiento de los criterios de elegibilidad y disposición". La persona trans debe demostrar que cumple una serie de criterios predefinidos para poder generar el cambio de su cuerpo y encontrase con su género. Así se entra en una paradoja (ND): "si somete se libera". Desde una biopolítica de los cuerpos, el mensaje es claro: el cuerpo es un territorio de poder del Estado y la ciencia. La persona trans queda vaciada de agencia (NPS).

\section{Homogeneizar o diferenciar para incluir}

Al trabajar en los programas y leyes que promueven la inclusión de la diversidad, aparentemente se estaría apostando por el valor de lo heterogéneo, por el respeto a lo diferente, por la defensa de los derechos de las minorías al igual que de las mayorías. 


\section{La utopía de la sociedad de iguales}

El texto de DCE tiene como objetivo trabajar por la inclusión de la diferencia, sin embargo, en todo el documento se opera con la lógica de homogeneizar y negar lo diverso. Así, al hablar de la educación se indica que: "Mejorar la calidad y la equidad de la educación en nuestro país es una aspiración sobre la cual existe consenso (...) que les permita aportar a la sociedad como ciudadanos responsables, respetuosos, solidarios y pacíficos". A simple vista, (NT) parece fácil aceptar que existe consenso sobre estos puntos, por lo mismo pasa sin mayor reflexión el que esta no sea entregada como una propuesta, sino como una norma. Se trabaja el discurso con la estrategia empirista del consenso tácito (ND), donde se supone que todos los chilenos comparten una misma visión de sociedad, de sujetos (ciudadanos) deseables y que la vía para lograrlo es la educación. Este acuerdo forzado busca homogeneizar las expectativas, negando el conflicto social existente; enmascarando así las tensiones políticas (NPS) existentes en Chile por las visiones disímiles y contrapuestas en torno a qué se espera de la educación y cómo debe lograrse. Se juega al mundo feliz, donde no hay disenso. Además, es posible inferir (implicatura) que esta negación porta una connotación del disenso y conflicto como algo negativo, poco pacífico y claramente no deseable (ND); por lo tanto, se genera una contradicción performativa ya que se declara que se apuesta por incluir la diferencia, al mismo tiempo que se busca abolir y negar las diferencias de opiniones.

Por otra parte, podemos leer en varias partes del texto DCE frases como: "un sistema educativo que debe transformarse y evolucionar para incluir esta diversidad, valorándola como una riqueza que fortalece el aprendizaje y el desarrollo de toda la comunidad educativa". Se mencionan (NT) a la escuela y la comunidad educativa como un genérico, sin matices ni referencias a los distintos lugares, comunas, ciudades, regiones. Se usa la estrategia de descontextualizar (ND) para así reificar la noción, generando un absoluto que permite unificar; negando otra vez precisamente las diversas realidades que se viven en las distintas escuelas y comunas de Chile (NRS).

\section{b) El imperio de la heteronorma}

En la Vía Clínica del Ministerio de Salud (VCAC) se hacen planteamientos interesantes y casi reflexivos: "La utilización de criterios diagnósticos del DSM-IV o CIE-10 no autoriza la estigmatización o la privación de derechos de las personas afectadas. La clasificación en estos manuales (DSM-IV y CIE-10) de las personas que manifiestan un sentimiento de incongruencia entre el sexo físico y la identidad de género, ha sido fuertemente cuestionada ya que es asociada a la estigmatización de la condición". Aquí podemos ver la presencia de una tensión discursiva (ND); ya que se presenta un discurso que acepta y reconoce la diferencia, pero al mismo tiempo transitamos por todo un programa de acción en salud que se funda en un diagnóstico y una adecuación a normas.

En este mismo plan de salud, se indica que: "si bien todos los estándares revisados recomiendan la realización de la EVR² (ver informe metodológico), es necesario tener presente la existencia de elementos propios del contexto nacional que pudieran dificultar la realización exitosa de ésta". Nos encontramos con otra tensión discursiva (ND), ya que aunque se indica que debe tenerse en cuenta el contexto cultural, más adelante se pide como requisito un progreso demostrable en la consolidación de la identidad de género. Así, la persona trans deberá demostrar que es capaz de lograr una adopción satisfactoria del rol del género con el cual la persona se identifica para poder acceder a las intervenciones y tratamiento hormonal. Por ende, se aprecia la circularidad (ND) en la que queda presa la persona transexual: (NPS) debe consolidar una identidad para operarse, y se opera para consolidar dicha identidad de género. Finalmente, se niegan las dificultades sociales y familiares que estas personas deben enfrentar.

A partir de la nueva ley que permite la unión de parejas en una condición distinta al matrimonio

2 La EVR corresponde a Experiencia de Vida Real, donde los sujetos deben demostrar que pueden llevar una vida normal con el género con el que se sienten identificados. Este es un criterio obligatorio para la elegibilidad para ser operado. 
(AUC), que fue promocionada y muy valorada por los movimientos de liberación LGTBI, se puede pensar que se abre un más amplio espectro de formas de pareja, de formas de familia, de aceptación de sexualidades diversas, de mayor inclusión, de superación de la heteronormatividad. Al revisar el documento, si bien se validan algunas de estas expectativas, la mayor parte de ellas quedan truncas. Se legitiman nuevas formas de pareja: "El acuerdo de unión civil es un contrato celebrado entre dos personas que comparten un hogar, con el propósito de regular los efectos jurídicos derivados de su vida afectiva en común, de carácter estable y permanente. Los contrayentes se denominarán convivientes civiles y serán considerados parientes”. Al hablar de personas y no de hombre y mujer, se abre la posibilidad de parejas distintas que puedan constituirse en familia. Pero la multiplicidad de familias queda acotada, cuando indica que no podrán constituirse como lazo familiar y con derecho a bienes y sucesión, aquellas personas que: "entre sí los ascendientes y descendientes por consanguinidad o por afinidad, ni los colaterales por consanguinidad en el segundo grado". Se indica así (NT) que existen lazos que son permitidos y otros que no lo son, para poder celebrar este pacto. Si bien en el cuerpo del texto mismo de la ley no habla ni de parejas ni de vínculo ni de amor ni de sexualidad, aparece aquí como una implicatura (ND) esta restricción de lazos de consanguinidad. Se erige la sexualidad como el elemento que debe unir, y desde una díada, a cualquier unión que quiera postular a la categoría de familia. La heteronorma se cuela no solo en esta lectura interpretativa de las aplicaciones pragmáticas de este pacto, sino también reivindicando atávicas tradiciones de dominio patriarcal: "Cuando un acuerdo de unión civil haya expirado, la mujer que está embarazada no podrá contraer matrimonio con un varón distinto ni celebrar un nuevo acuerdo antes del parto, o, no habiendo señales de preñez, antes de cumplirse los doscientos setenta días subsiguientes a la expiración del acuerdo". Entonces, se subraya nuevamente en este contexto de apertura el dominio del Estado sobre el cuerpo de la mujer y la defensa de los derechos del varón.
Se marca la inclusión de los convivientes civiles añandiéndolos en muchas leyes, a la vez que se diferencia claramente de conyuges, en los mismos artículos. Se vincula el acuerdo de unión civil con el matrimonio, pero a la vez se busca enfatizar sus diferencias (NT). Así se busca (NPS) tranquilizar a quienes temen que este tipo de normativas quiebren a la familia y al matrimonio como institución tradicional.

\section{Diferenciar para excluir}

La ley contra la discriminación (LND) plantea una contradicción o negación interna de la ley: "Se considerarán razonables las distinciones, exclusiones o restricciones que, no obstante fundarse en alguno de los criterios mencionados en el inciso primero, se encuentren justificadas en el ejercicio legítimo de otro derecho fundamental". Se establece así una diferenciación entre derechos de primera y de segunda categoría; si bien aparentemente previene el que se vulnere un derecho fundamental, lo que el texto hace es generar una contradicción argumentativa y performativa (ND), ya que limita un derecho que pareciera estar otorgando al añadir esa condición, y en consecuencia podrá considerarse en la práctica que hay otros derechos más relevantes que el ser un sujeto de derecho al no ser reconocido como tal.

Por su parte, en la VCAC también aparece una distinción relevante con respecto a la aplicación del programa que esta normativa define. Así se indica que: "La baja incidencia de este problema de salud podría dificultar la activación adecuada del conjunto de prestaciones señaladas en esta Vía Clínica, en especial desde los servicios de salud mental de los niveles secundarios de atención". Primero, (ND) se prescribe de manera anticipada lo difícil que será llevar a cabo la normativa que el mismo documento define que se debe realizar, es decir, la misma norma se desactiva antes de ser implementada. Y se utiliza un valor supuestamente de consenso en el mundo médico (ND), la prevalencia, para fundamentar por qué es probable que no sea viable este tratamiento. Entonces, las demandas de las minorías tienen menor importancia, a la vez que esta demanda claramente logre salir del silencio tampoco es facilitado por la censura social (NPS). 


\section{Conclusiones}

Los objetivos y preguntas que se plantearon en este estudio se orientaron principalmente a revisar el posicionamiento del poder y los enunciados acerca de la diversidad que aparecen tejidos en la textualidad de los cuatro documentos de políticas públicas analizados. Es posible plantear, entonces, que no se supera la heteronormatividad, ya que si bien se avanza en algunas inclusiones y oportunidades, estas políticas han sido confeccionadas desde límites frágiles donde no se pone en juego la hegemonía de las sexualidades y se deja intacto el heterosexismo, los binarismos, el control sobre los cuerpos y la concepción de familia heterosexual como el centro articulador de toda política del Estado.

Así, en los documentos de la Vía Clínica para adecuación corporal y el Acuerdo de Unión Civil se evidencia que al intentar incluir a "los otros" dentro de sus programas y acciones, el poder público solo les concede lugares de tercera y cuarta categoría. Al introducir la existencia de "los diversos" recategorizan estableciendo una nueva jerarquía que se debe aceptar para poder obtener los derechos prometidos. Se confirma así lo que ya han señalado estudios anteriores, al indicar la permanencia de marcos heteronormativos en las políticas públicas en pro de la diversidad sexual (Cunial \& Palumbo, 2014). Como señala Butler (2007, 2009b) generar regulaciones que logren ir más allá de los regímenes de verdad que norman a los mismos sujetos LGTBI se hace muy difícil; por lo mismo, en estos nuevos programas y acuerdos se cuelan las normalizaciones hegemónicas contra las que se lucha. Incluso, quienes buscan proponer nuevas identificaciones caen en el mismo juego binario y opresor.

Así, si bien la transexualidad aparece como un espacio de transgresión de las normas de género que imposibilitaría constituir definiciones estables y coherentes, esto se contradice ferozmente con los procedimientos que el Ministerio de Salud define para que las personas trans puedan realizar una modificación de sus cuerpos, ya que si bien abre un puerta desde los derechos a intervernir sobre sus cuerpos sexuados, al mismo tiempo tramita esta modificación a través de las usanzas más extremas y controladoras de las biopolíticas hegemónicas. Para obtener la ayuda médica, deberán asilarse a la última de las patologizaciones mantenidas por los manuales diagnósticos de salud mental, entregando sus deseos y cuerpos al juicio y evaluación de un sistema que los obliga a demostrar ser los más adaptados de los abyectos.

Este precio, si bien puede valer la pena para muchas personas que sufren por vivir en medio de rechazos y contradicciones que parten desde su propia materialidad, también aparece como una traición de quienes precisamente parecerían evidenciar una de las mayores desobediencias contra las intenciones de domesticar las sexualidades (MartínezGuzmán \& Íñiguez-Rueda, 2010). Por tanto, como se ha señalado desde los defensores de la disidencia sexual, esta misma subversión genera que la biopolítica los castigue desde la heterosexualización y normalización de estos cuerpos, generando odio y rechazo hacia su propia genitalidad, para lograr solo a través de la intervención quirúrgica y hormonal la aceptación social (CUDS, 2011).

Por su parte, el Acuerdo de Unión Civil sigue normando el tipo de vínculos que las personas pueden declarar y los derechos a los que pueden aspirar; así al generar una nueva categoría de estado civil, se amplían las legitimidades y se confirman las prerrogativas para delimitar e imponer el lugar de la sexualidad y los formatos de familia posibles. Al pedir un derecho, se entrega también mayor dominio al Estado; la institucionalidad y los valores de la heteronormatividad se imponen, tal como han señalado varios autores (Butler, 2007; Martínez-Guzmán \& Íñiguez-Rueda, 2010; ToroAlfonso, 2014).

Tampoco en los intentos que han introducido los grupos LGTBI dentro de la educación, se logra atacar la esfera desde donde se producen las pautas sociales de interacción. En la pretensión de incluir la diferencia, se fortalece la desprotección de la diversidad al volver a situarla desde una otredad, ya que no se logra instalar la idea de un nosotros que incluya lo diverso, solo se alcanza a un respeto parcial hacia otro, pero no la aceptación y valoración de la diferencia (Butler, 2009b). 
Con respecto a la circulación del poder, es posible plantear que los lugares de poder permanecen, en general, en las posiciones hegemónicas tradicionales de la sociedad. Las estrategias discursivas analizadas evidenciaron que el médico y el juez reafirman aún más sus prerrogativas de definir acerca de la vida de estos sujetos (Butler, 2007; MartínezGuzmán \& Íñiguez-Rueda, 2010).

Por su parte, la ley de no discriminación y el programa para las escuelas evidencian la dificultad de operar con una difusa noción de discriminación, al mismo tiempo que testimonian la presencia de los resquicios propios de la institucionalidad, para despojar de poder a los sujetos que se someten a ella. La escuela, con la intención salvadora de procurar un espacio seguro a los estudiantes discriminados, los ubica en la mayor de las pasividades, desdibujando los espacios y autonomías que estos mismos sujetos ya han conquistado. La institución jurídica vuelve a usar la estrategia de cubrirse los ojos a fin de ser justo, generando ambigüedades y contradicciones que impiden ahora apelar a normativas internacionales más inclusivas, las que son negadas con este nuevo avance legal (Díaz-García, 2013). Sumado a esto, la ley no fija medidas más concretas sobre la discriminación, dejando al arbitrio de la interpretación de un juez el determinar si la acción debería considerarse como discriminación arbitraria o no.

En consecuencia, estas políticas tan solo posibilitan a un cierto sujeto en subordinación hegemónica, donde los diversos son situados en la precariedad (Butler, 2009a) y mantienen su exclusión a pesar de la renormativización. Así, estas iniciativas se acomodan solo a algunos sectores de la diversidad sexual, aquellos que desde la misma lógica se sienten reconocidos, pero abre la brecha entre los debates de los extremos de la disidencia. Así, quienes no logran "caber" dentro de los espacios que la heteronormatividad tolerante abre, siguen siendo nominados como lo abyecto, aquello que nos provoca e invita, desde fuera de los márgenes, a desatar los cuerpos (Braidotti, 2000).

Sin perjuicio de lo antes señalado, es importante afirmar que este trabajo no pretendió realizar una "evaluación" de estas políticas y sus logros. Por lo mismo, no se trabajó en la línea de mostrar los avances y aportes que sí traen estas normativas tanto al haber propiciado una discusión y un debate social en torno a los derechos de las diversidades sexuales, como el impacto mismo que puede traer la implementación y aplicación de estas políticas. Esta limitación se menciona para visibilizar que el aporte de este estudio no va en la línea de evaluar en términos globales y amplios el quehacer de los gobiernos chilenos en torno al reconocimiento y protección de las llamadas minorías sexuales, sino que precisamente la contribución que se busca propiciar se vincula con las pretensiones propias del dispositivo del ACD. Se apuesta, entonces, por complejizar la visión de las diversidades sexuales, abogando por escapar de la ingenuidad del conocimiento como producción neutral (Stecher, 2010; Van Dijk, 2000). Así, se intenta avanzar hacia una psicología contrahegemónica que genere nuevos discursos, propiciadores de nuevas categorías que tensionen la lógica heteronormativa excluyente y controladora. En este contexto, se concuerda con Flores (2011) en cuanto a que la psicología debe asumir su compromiso con los excluidos y con todos y "(...caminar en contrasentido a la estructura de poder que degrada y pisotea la dignidad humana" (p. 64).

A modo de reflexiones finales y en la línea de abrir nuevas preguntas e itinerarios de indagaciones posibles, es pertinente plantear algunas comprensiones que se han generado a partir de este estudio, y que parecieran fértiles para dejar abiertas diversas discusiones.

¿Podría existir un reconocimiento que supere la tensión entre lo universal y lo singular?, ¿Existen políticas públicas que desde este lugar hegemónico puedan romper el destino impositivo y opresor que todo acto de institucionalización conlleva?, iSe puede luchar por los derechos y el reconocimiento de los LGTBI si la misma sigla porta una clausura y ancla en una lógica identitaria que suele traicionarse a sí misma?, ¿Se hace necesario dar un paso al lado, para reconstruir las posibilidades desde las provocaciones que la vía de la disidencia propone?

Pareciera que dentro de los intentos de generar aperturas a lo diverso, se observa que más bien se han producido nuevas prácticas y discursos que solo se sofistican y mutan, pero permanecen dentro 
de la lógica de la discriminación; esto se fundaría en la fuerza de una suerte de homogeneización naturalizada que busca persistentemente eliminar las señas de la diferencia (Toro-Alfonso, 2012). Desde allí, es posible señalar que al parecer existiría en nuestras sociedades una construcción permanente de una "otredad" donde se deposita lo monstruoso, lo abyecto y lo temido que posiblemente no queremos reconocer en el mismo "nosotros". Por lo tanto, siempre será posible instaurar un nuevo otro que devenga en receptáculo de la exclusión.

Aparece, entonces, la necesidad de trabajar en la noción de otredad y situarnos en el camino de la pregunta ética, como vías necesarias y auxiliadoras. Para esto, se propone tomar elementos propuestos por Butler (2009b) y dialogar con Spivak (1998). Al interrogarnos acerca de "icómo debería yo tratar a otro?” quedamos, según Butler (2009b), inmediatamente atrapados en el marco de la normatividad social. En el intento de buscar resguardo y legitimación de los derechos y dignidad de los otros, nos convertimos en instrumento de la agencia de la norma; es decir, al luchar por nuevas normas terminamos siendo usados por estas normas. Así también, el cuestionar las normas vigentes de reconocimiento se abre la posibilidad de caer también en la esfera de los no reconocibles.

Spivak (1998), por su parte, critica las políticas identitarias y en contraposición propone una noción de sujeto descentrado, que nunca se podría atrapar en una lógica de la identidad. En esta línea, la autora propone valorar el uso estratégico de acción política de estas categorías identitarias. Por otra parte, como poscolonialista, subraya la necesidad de trazar un itinerario del silencio, un camino de inclusión en el discurso del sujeto subalterno para que este pueda acceder a un lugar de enunciación que le permita situarse desde un espacio donde pueda ser reconocido y escuchado.

Tomando estos aportes, es posible pensar que la lucha de las personas LGTBI puede y debe transitar siempre dentro de una incredulidad de la propia pertenencia a esta categoría; a fin de no fijarse en una identidad que por sí misma limita sus posibilidades como sujeto, es definida desde la heteronorma y supone quedar instalado en el lugar de la otredad, una otredad más digna o menos discriminada, pero siempre un otro. Así también, el asumir que solo estos cuerpos portan deseos abyectos, trae consigo la atractiva promesa para las hegemonías conservadoras, de poder extirpar los deseos otros de las materialidades situadas en el nosotros.

\section{Referencias}

Alfaro, J., \& Zambrano, A. (2009). Psicología comunitaria y políticas sociales en Chile. Psicología y Sociedad, 21(2), 275-282.

Braidotti, R. (2000). Sujetos nómades. Buenos Aires: Paidós.

Butler, J. (2007). El género en disputa. El feminismo y la subversión de la identidad. Madrid: Paidós.

Butler, J. (2009a). Performatividad, precariedad y políticas sexuales. Revista de Antropología Iberoamericana, 4(3), 321-336. Recuperado de http://redalyc.uaemex.mx/src/inicio/ArtPdfRed. jsp?iCve $=62312914003$

Butler, J. (2009b). Dar cuenta de símismo. Violencia ética y responsabilidad. Buenos Aires: Amorrortu.

Coordinadora Universitaria por la Disidencia Sexual. (2011). Por un feminismo sin mujeres. Santiago: Territorios Sexuales Ediciones.

Cunial, S., \& Palumbo, M. (2014). Sexualidad, salud y sociedad. Revista Latinoamericana, 16, 173-180.

De La Fuente García, M. (2004). Análisis crítico del discurso y racismo en los medios de comunicación. En M. Villayandre (Ed.), Actas del V Congreso de Lingüística General (pp. 1047-1057). Madrid: Arco Libros. Disponible en http://www.mariodelafuente. org/documentos/analisis-critico-del-discurso-yracismo-en-los-medios-de-comunicacion.pdf

Díaz García, I. (2013). Ley chilena contra la discriminación: una evaluación desde los derechos internacional y constitucional. Revista Chilena de Derecho, 40(2), 635-668. Recuperado de: http:// www.redalyc.org/articulo.oa?id=177029687011

Esguerra, C., \& Bello, J. (2014). Interseccionalidad y políticas públicas LGBTI en Colombia: usos y desplazamientos de una noción crítica. Revistas de Estudios Sociales, 49, 19-32. doi: 10.7440/ res49.2014.02 
Flores, J. (2011). Psicología y praxis comunitaria una visión latinoamericana. México: Editorial Latinoamericana.

Forero, J., \& Hurtado, D. (2013). ACD: una propuesta para el análisis de política pública de género. Discurso $\mathbb{E}$ Sociedad, 7(2), 257-289.

Kozak, G. (2006). iEstudios sobre diversidad sexual, estudios sobre minorías sexuales? Revista Venezolana de Economía y Ciencias Sociales, 12(3), 135-141.

Krause, M. (1995). La investigación cualitativa - Un campo de posibilidades y desafíos. Revista Temas de Educación, 7, 19-39.

Lahera, E. (2008). Introducción a las políticas públicas. En E. Lahera (Ed.), Características frecuentes de las políticas públicas actuales (pp. 23-27). Santiago: Fondo de Cultura Económica.

Martín Rojo, L. (2003) El análisis crítico del discurso. Fronteras y exclusión social en los discursos racistas. En L. Íñiguez (Ed.), Análisis del Discurso. Manual para las ciencias sociales (pp. 157-191). Barcelona: Editorial UOC. Disponible en http:/ pendientedemigracion.ucm.es/info/circulo/no20/ iniguez.htm

Martínez-Guzmán, A., \& Íñiguez-Rueda, L. (2010). La fabricación del trastorno de identidad sexual. Discurso E Sociedad, 4(1), 30-51.

Mogrovejo, N. (2008). Diversidad sexual, un concepto problemático. Revista Trabajo Social, 18, 62-71.
Movimiento de Integración y Liberación Homosexual. (2014) Informe anual de derechos humanos de la diversidad sexual en Chile. Santiago: Autor.

Potter, J. (1998). La representación de la realidad. Barcelona: Paidós.

Rivas, E. (2014). Patologización de la diversidad sexual, en los sistemas de clasificación. Recuperado de http:// mums.cl/2014/05/patologizacion-de-la-diversidadsexual-en-los-sistemas-de-clasificacion/

Rozas, G. (2014). Repensar la psicología y lo comunitario en América Latina. En J. Flores (Ed.), De las políticas sociales hacia las políticas de reconocimiento en comunidades latinoamericanas (pp. 107-138). Tijuana: Editorial Latinoamericana.

Spivak, G. C. (1998). ¿Puede hablar el sujeto subalterno? Orbis Tertius, 3(6), 175-235. Recuperado de http:// www.fuentesmemoria.fahce.unlp.edu.ar/art_revistas/pr.2732/pr.2732.pdf

Stecher, A. (2010). El análisis crítico del discurso como herramienta de investigación psicosocial del mundo del trabajo. Discusiones desde América Latina. Universitas Psychologica, 9(1), 93-107.

Toro-Alfonso, J. (2012). El estado actual de la investigación sobre la discriminación sexual. Terapia Psicológica, 30(2), 71-76.

Van Dijk, T. (2000). El estudio del discurso. En T. Van Dijk (Comp.), El discurso como estructura y proceso (pp. 21-65). Barcelona: Gedisa. 